\title{
Easier to Twist than Bend: The Scope of the Bridge Formation Approach to Naphthalenophane Synthesis
}

\author{
Anjan Bedi * (D) \\ Linda J. W. Shimon ${ }^{b}$ (i) \\ Benny Bogoslavsky ${ }^{a}$ (iD) \\ Ori Gidron $^{\mathrm{a} *}$ (1D) \\ a Institute of Chemistry, The Hebrew University of Jerusalem, Edmond J. Safra Campus, \\ Jerusalem, Israel \\ ${ }^{\mathrm{b}}$ Chemical Research Support Unit, Weizmann Institute of Science, Rehovot, Israel \\ anjan.bedi@mail.huji.ac.il; ori.gidron@mail.huji.ac.il
}

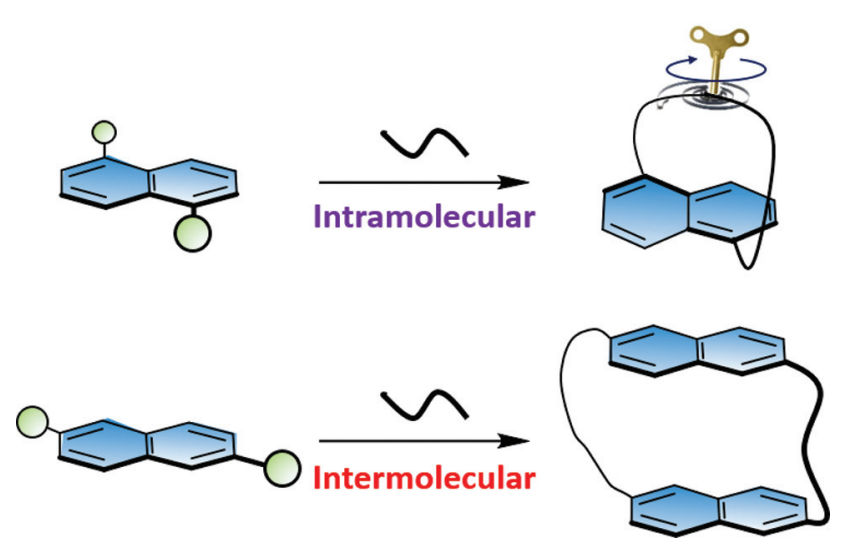

additional way to side-group modifications for controlling their properties. ${ }^{3}$ Twisting polyaromatic molecules out of planarity often induces chirality, giving rise to new chiroptical and magnetic properties. ${ }^{4}$

The second smallest acene, naphthalene, often serves as a simpler model than higher acenes and therefore studying naphthalene can elucidate the factors related to structurefunction relations in higher acenes. ${ }^{5}$ Twisted naphthalenes were among the first twisted acenes to be investigated. ${ }^{6}$ For example, octamethylnaphthalene exhibits an end-to-end twist of $26^{\circ},{ }^{7}$ and even two substituents (in the peri-positions) can induce naphthalene to twist significantly, as demonstrated by 1,8 -bis(1-adamantyl)naphthalene, twisted to $28.4^{\circ}$. $^{8}$

An alternative way to induce twist is by the strain imposed by covalently linking the end positions in acene, thereby creating an acenophane. ${ }^{9}$ Haenel and coworkers have previously demonstrated a bridge contraction method for obtaining twisted naphthalenophane. ${ }^{10,11}$ Bodwell's group has recently demonstrated the method of "contractive annulation" for the synthesis of curved 1,6-naphthalenophane, in which the polyaromatic moiety is expanded after bridge formation. ${ }^{12}$

We have previously prepared a series of helically locked tethered twisted acenes, in which the end-to-end twist is tuned by the tether length. ${ }^{13}$ In this manner, we produced Ant-Cn enantiomers that were helically locked into stable $M$ and $P$ conformations by the tether, which prevents rotation around the backbone and thus forestalls racemization, while defining the degree of backbone twist and minimizing substituent effects. We found that, as the twist angle increased, the fluorescence quantum efficiency $\left(\phi_{\mathrm{f}}\right)$, halflife time $\left(\tau_{\mathrm{f}}\right)$, and optical band gap of Ant-Cn systematically decreased, while the Cotton effect and absorption anisotropy factor systematically increased. ${ }^{14}$ In addition, we found that charge delocalization is not affected significantly by 


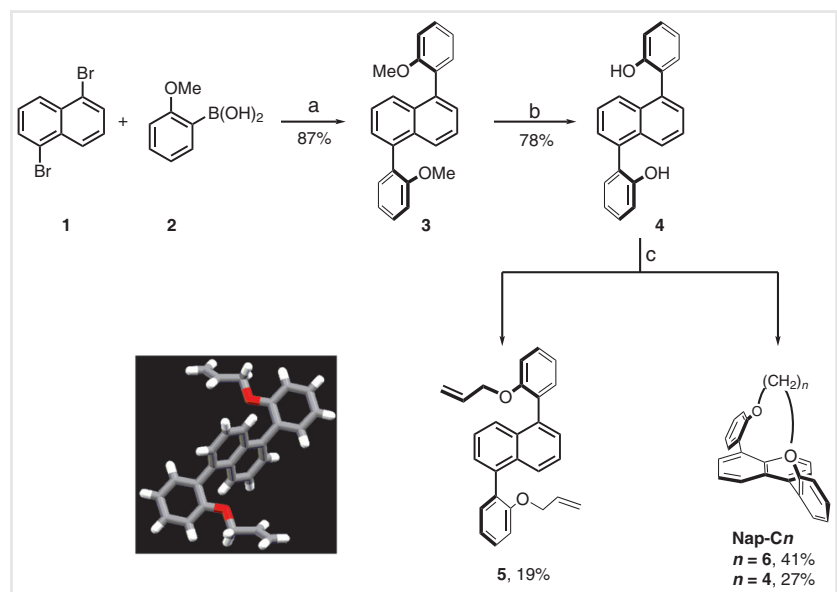

Scheme 1 Synthetic pathway to Nap-Cn. Conditions: (a) $\mathrm{Pd}\left(\mathrm{PPh}_{3}\right)_{4}$, $\mathrm{Na}_{2} \mathrm{CO}_{3}$, dioxane/water; (b) $\mathrm{BBr}_{3}$, dichloromethane, $0{ }^{\circ} \mathrm{C} \rightarrow \mathrm{RT}$; (c) $\mathrm{BrCH}_{2}\left(\mathrm{CH}_{2}\right)_{n-2} \mathrm{CH}_{2} \mathrm{Br}(n=3,4,6), \mathrm{KOH}$, DMSO (i.e., dimethyl sulfoxide). Bottom left: X-ray structure of $\mathbf{5}$.

twisting. ${ }^{15}$ Following that work, we were interested in exploring the effect of twisting (measured by the dihedral angle of carbons at the 2, 3,6 , and 7-positions) and bending (measured by the distance between the carbons at 2-7- and 3-6-positions) using the tethering approach on acenes of different lengths.

In the current work, we describe the scope of the bridge formation approach to synthesis in the context of axially chiral naphthalenes bearing two substituents at either the 1,5- or 2,6-positions (Schemes 1 and 2). We find that bridge formation at the 1,5-positions proceeds to form mildly twisted naphthalenes, twisted by $6^{\circ}$ and $12^{\circ}$, as verified by their solid-state structures. The optical and chiroptical properties of the twisted naphthalenes, studied both experimentally and computationally, show increases in both extinction coefficient and Cotton effect with increasing twisting, in a manner similar to that observed for longer acenes. Attempts to form bent 2,6-naphthalenophanes resulted in inter- rather than intramolecular coupling, with the single crystal product displaying a $D_{2}$ symmetric structure.

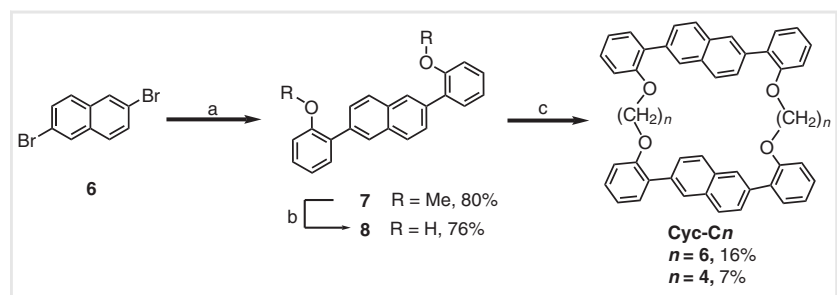

Scheme 2 Synthetic pathway to Cyc-Cn. Conditions: (a) $\mathrm{Pd}\left(\mathrm{PPh}_{3}\right)_{4}$, $\mathrm{Na}_{2} \mathrm{CO}_{3}$, dioxane/water; (b) $\mathrm{BBr}_{3}$, dichloromethane, $0{ }^{\circ} \mathrm{C} \rightarrow \mathrm{RT}$; (c) $\mathrm{BrCH}_{2}\left(\mathrm{CH}_{2}\right)_{n-2} \mathrm{CH}_{2} \mathrm{Br}(n=4,6)$, $\mathrm{KOH}$, DMSO.

\section{Results and Discussion}

\section{Synthesis and NMR Characterization}

1,5-Naphthalenophanes Nap-C4 and Nap-C6, bearing butyl and hexyl tethers, respectively, in the 1,5-positions, were synthesized starting from the Suzuki coupling of 1,5dibromonaphthalene $\mathbf{1}$ with ortho-anisole boronic acid $\mathbf{2}$ (Scheme 1). The diol obtained after ether cleavage with $\mathrm{BBr}_{3}$ (4) was subjected to Williamson ether synthesis with $\mathrm{BrCH}_{2}\left(\mathrm{CH}_{2}\right)_{n-2} \mathrm{CH}_{2} \mathrm{Br}$, where $n=3,4$, and 6. For dibromobutane and dibromohexane, the reaction proceeded in an intramolecular fashion, yielding Nap-C4 and Nap-C6, respectively. Racemic mixtures of Nap-Cn were separated using chiral HPLC. In contrast, the reaction of $\mathbf{4}$ with dibromopropane did not yield the expected Nap-C3. Instead, the Williamson reaction was followed by elimination to yield the di-alkene product, $\mathbf{6}$, whose structure was also verified by X-ray crystallography (Scheme 1, bottom left).

To introduce bending (rather than twisted) acenes, we attempted to apply the same synthetic methodology to the tethering of naphthalene in the 2,6-positions (Scheme 2). To this end, we prepared 2,6-bis(orthophenol)naphthalene (8) from 2,6-dibromonaphthalene (6) by Suzuki coupling, followed by treating with $\mathrm{BBr}_{3}$. Attempts to apply Williamson ether synthesis with dibromobutane and dibromohexane resulted in intermolecular (rather than intramolecular) reactions that produced Cyc-C6 and Cyc-C4 with 16\% and 7\% yields, respectively, where the main product was an insoluble polymer. It is interesting to note that, previously, 2,6-tethering of naphthalene was achieved using ring contraction tactics (nucleophilic substitution to obtain unstrained precursor, followed by double-Stevens rearrangement and thermal elimination). ${ }^{11}$ It is therefore clear that in the absence of any preorganization, the strain energy for bending is too high for direct tethering using Williamson ether synthesis.

Cyclophanes Nap-C4 and Nap-C6 were fully characterized by NMR, HRMS, and X-ray crystallography. The diastereotopic bridging methylene protons undergo a different chemical shift for Nap-C4 compared with NapC6, as was previously observed for different bridge lengths in the Ant-Cn series. Furthermore, for Nap-C6, these two diastereotopic protons also overlap as they lie in similar chemical environments. For $\mathbf{C y c - C 4}$, the methylene protons are not diastereotopic, but rather homotopic [Figure S66, see Supporting Information (SI)], and the protons at the 2"position (Figure 1) are not shielded by the paratropic ring current, as for Nap-Cn, which provides an additional indication that these protons, which are at $1.9 \mathrm{ppm}$ (in contrast to 0.6 and 0.8 ppm for Nap-C4), are distant from the naphthalene moiety. 
(a)
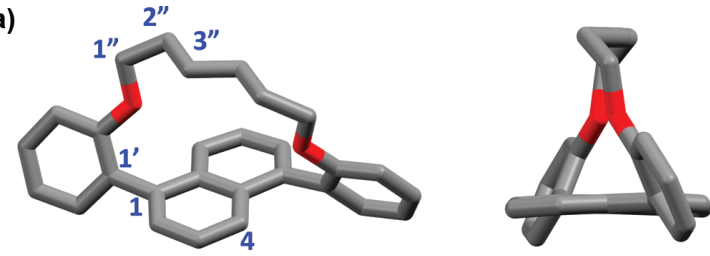

(b)
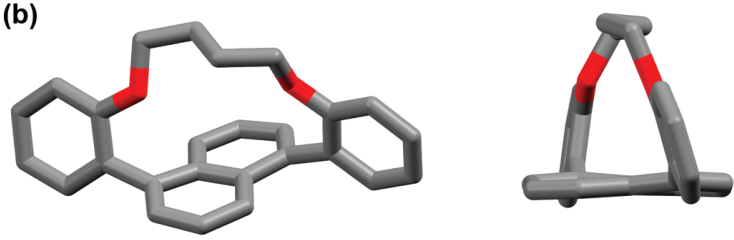

(c)
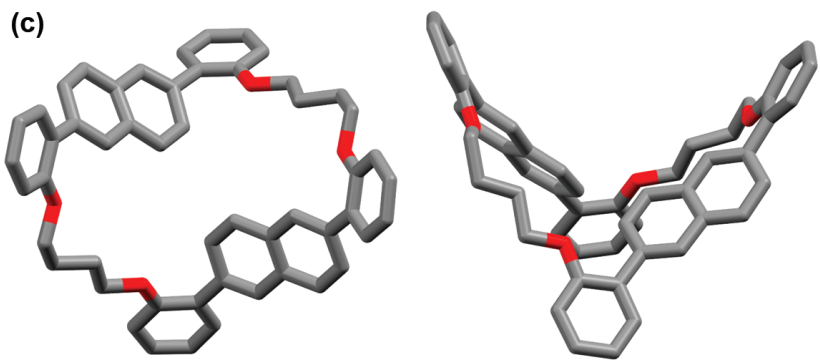

Figure 1 X-ray structures of (a) Nap-C6, (b) Nap-C4, and (c) Cyc-C4. Hydrogens are omitted for clarity.

\section{Single-Crystal X-Ray Structures}

Both Nap-C4 and -C6 were recrystallized in hexane-ethyl acetate to yield colorless needles. The X-ray structures of NapC4 and -C6 are depicted in Figure 1a and b, respectively. The length of the bridging alkyl affects the dihedral angle between the ortho-anisole groups and the naphthalene as well as the end-to-end twisting of the naphthalene core, which increases from $6^{\circ}$ to $11^{\circ}$ as the tether length decreases. This is consistent with the calculated structures [optimized at the DFT/B3LYP/6$31 \mathrm{G}(\mathrm{d})$ level of theory], for which the end-to-end twisting increases from $6^{\circ}$ to $12^{\circ}$ with decreasing tether length. An additional difference between Nap-C4 and -C6 is the deviation of the $\angle \mathrm{C} 4-\mathrm{C} 1-\mathrm{C} 1^{\prime}$ angle from $180^{\circ}$, with this angle being $165^{\circ}$ in Nap-C4, and increasing to $167-175^{\circ}$ in Nap-C6 (Figure 1a). The X-ray structure of Cyc-C4 (obtained from chloroform/ hexane as colorless plate) reveals a racemate consisting of two $D_{2}$ symmetric cyclophanes in a unit cell (Figure 1c). However, unlike the $C_{2}$ symmetric Nap-Cn, the structure of Cyc-C4 is flexible, as there can be free rotation around the naphthaleneanisole bond, leading to racemization.

\section{UV-Vis Absorption and ECD Spectroscopy}

The absorption spectra of Nap-Cn are composed of three observable bands (Figure 2a). The lowest energy band bathochromically shifts as the tether shortens, from

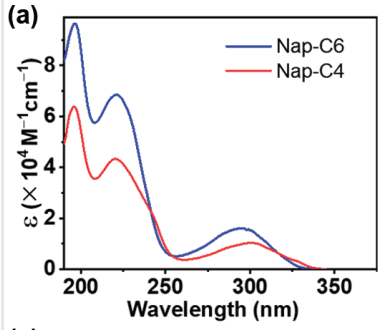

(c)

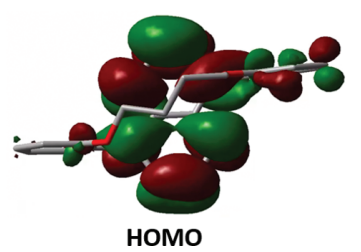

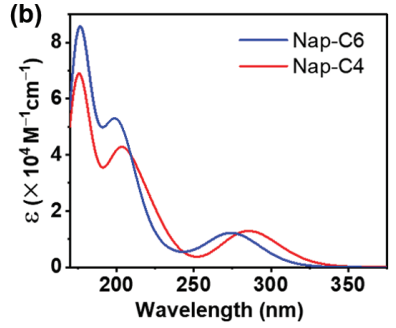

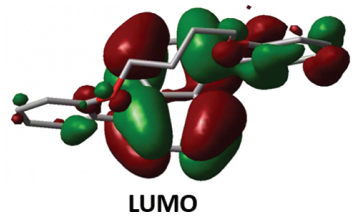

Figure 2 (a) Experimental and (b) computational [TD-DFT/CAM-B3LYP/ 6-31G(d) level] UV-Vis absorption spectra of Nap-C4 (red) and Nap-C6 (blue), measured in acetonitrile. (c) Calculated HOMO and LUMO orbitals for Nap-C4.

$295 \mathrm{~nm}$ for Nap-C6 to $300 \mathrm{~nm}$ for Nap-C4. This shift cannot be explained by the naphthalene-anisole twist, as the dihedral angle increases for shorter tethers, thus reducing conjugation (the average value for the naphthalene-anisole dihedral angle is $64^{\circ}$ for Nap-C4 and $74^{\circ}$ for Nap-C6). Therefore, it is reasonable to assume that the shift results from a smaller HOMO-LUMO gap caused by naphthalene backbone twisting, as previously observed for longer acenes. ${ }^{13}$

TD-DFT calculation successfully reproduces the experimental spectra (Figure 2b). Analysis of the lowest energy transition shows that it is composed principally of the HOMO $\rightarrow$ LUMO transition, mainly centered on the naphthalene backbone, which strengthens the aforementioned supposition regarding the origin of this transition (Figure 2c). The change in the HOMO and LUMO levels with twist also provides explanation to the bathochromic shift observed above: while the HOMO level remains similar in both Nap-C6 and Nap-C4, the LUMO of Nap-C4 is lower by $0.16 \mathrm{eV}$ (the LUMO levels are -0.83 and $-0.99 \mathrm{eV}$ for NapC6 and Nap-C4, respectively). This is expected as the $\mathrm{sp}^{2}$ carbons are distorted out of planarity, resulting in increasing $s$ character of the $\pi$-orbitals. ${ }^{3,16}$

The bands at 220 and $196 \mathrm{~nm}$ show trends similar to those observed for the lowest energy transition, namely a bathochromic shift and lower extinction coefficient for shorter tethers. However, computational analysis reveals that these bands also include significant contributions from the anisole side groups (see SI). We therefore limit our discussion to the lowest energy band. Both Cyc-C4 and CycC6 display similar absorption spectra, since the naphthalene core in both cases remains planar, as expected.

The electronic circular dichroism (ECD) spectra for Nap$\mathbf{C n}$ are shown in Figure 3a. The most important observation is that, despite the smaller extinction coefficient for Nap-C4, the 

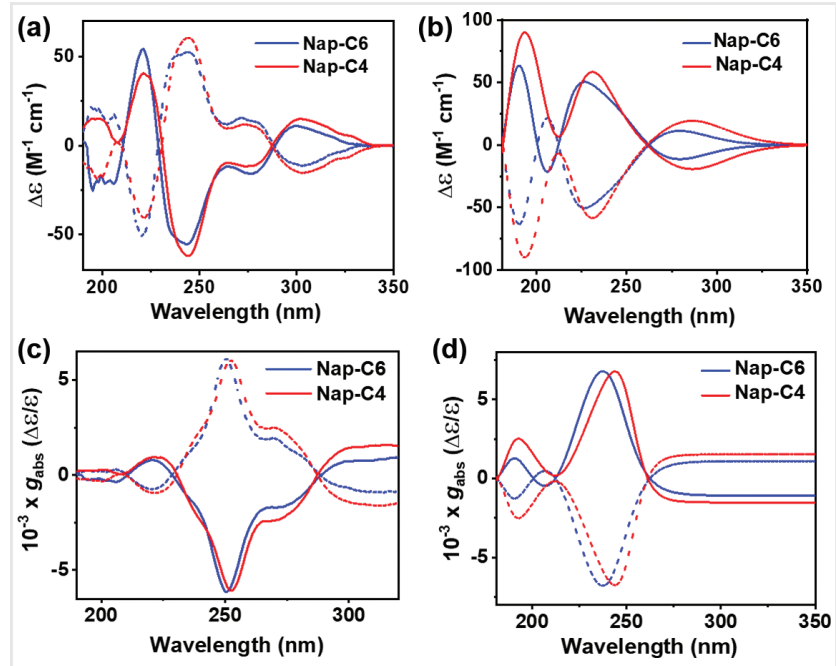

Figure 3 (a) Experimental and (b) computational [TD-DFT/CAM-B3LYP/ 6-31G(d) level] ECD spectra of Nap-C4 (red) and Nap-C6 (blue). (c) Experimental and (d) computational anisotropy factor. Solid: $P$ enantiomers, dashed: $M$ enantiomers. All measured in acetonitrile at room temperature.

$\Delta \varepsilon$ is larger compared with the longer tether, Nap-C6 for the lowest energy band centered around $300 \mathrm{~nm}$. This demonstrates that even a small increase in backbone twisting can result in more intense chiroptical properties. The computational ECD spectra are consistent with the experimental spectra, displaying an increase in intensity of about $60 \%$ for the lowest energy band as twisting increases (Figure $3 \mathrm{~b}$ ). The reason for this increase in intensity is an increase in the electric transition dipole moment for the lowest energy transition (Figure S70, see SI). The anisotropy factor ( $g_{\text {abs }}$; Figure $3 \mathrm{c}$ and $\mathrm{d}$ for experimental and computational spectra) reaches a maximum of $6 \times 10^{-3}$, which is similar in magnitude to those of the longer [5]helicene and [6] helicene $\left(4-9 \times 10^{-3}\right)$. Overall, even small twist of the naphthalene backbone can result in significant changes in its chiroptical properties, rendering a twisted naphthalene moiety as an interesting candidate for chiroptical applications.

\section{Conclusions}

We introduced two enantiomerically pure naphthalenophanes bearing butyl and hexyl tethers, Nap-C4 and Nap-C6. Attempts to obtain a larger twist by tethering shorter alkyls resulted in elimination rather than additional intramolecular coupling. This highlights the importance of steric hindrance prior to bridge formation (preliminary twist) for obtaining highly twisted acenes. Utilizing the same tether lengths, attempts to tether at the 2,6-positions to obtain bent naphthalenophanes resulted in intermolecular dimerization to yield cyclophanes Cyc-C4 and Cyc-C6. For Nap-Cn, the degree of backbone twisting is greater for shorter tethers, and this is reflected in a bathochromic shift of the lowest energy transition as observed for longer acenes. DFT calculations indicate that this results from lowering of the LUMO level as twisting increases. For enantiopure Nap-Cn, the Cotton effect increases with twist, and even a small twist is sufficient for obtaining significant anisotropy factors, similar to that observed in much longer helicenes.

\section{Experimental Section}

All chemicals purchased were reagent grade and were used without further purification. Compounds 1,5-dibromonaphthalene $(\mathbf{1})^{17}$ and 2-methoxyphenylboronic acid $(\mathbf{2})^{18}$ were synthesized according to the previously reported procedures. Compound 6 was purchased from Aldrich. Flash chromatography (FC) was performed using a CombiFlash EZ-Prep and $\mathrm{SiO}_{2}$ columns. Chiral HPLC separations were performed at room temperature (RT) with a Chiralpak IG semipreparative column, with hexane/dichloromethane (DCM) (85/15) as an eluent. ${ }^{1} \mathrm{H}$ NMR and ${ }^{13} \mathrm{CNMR}$ spectra were recorded on Bruker AV 400 and Bruker AV 500 spectrometers. Residual solvent peaks were used as internal references. UV-Vis absorption spectra were recorded with an Agilent Cary-5000 spectrophotometer. The spectra were measured using a quartz cuvette $(1 \mathrm{~cm})$ at $25^{\circ} \mathrm{C}$. The absorption wavelengths are reported in $\mathrm{nm}$ with the extinction coefficient $\varepsilon\left(\mathrm{M}^{-1} \mathrm{~cm}^{-1}\right)$ given in brackets. ECD spectra were recorded on an MOS-500 spectrophotometer from BioLogic Science Instruments. High-resolution mass spectra were analyzed on an Agilent HR Q-TOF-MS mass spectrometer using the dual-ESI technique operating in the positive mode. MALDI-TOF-MS spectra were acquired using a MALDI-TOF/TOF autoflex speed mass spectrometer (Bruker Daltonik GmbH, Bremen, Germany), which is equipped with a smartbeam-II solid-state laser (modified Nd:YAG laser), $\lambda=355 \mathrm{~nm}$. The instrument was operated in the positive ion reflectron mode. The accelerating voltage was $21.0 \mathrm{kV}$. The delay time was $130 \mathrm{~ns}$. Laser fluences were optimized for each sample. The laser was fired at a frequency of 2 kilohertz and spectra were accumulated in multiples of 500 laser shots, with 1500 shots in total. Sample preparation: 2-[(2E)-3-(4tert-butylphenyl)-2-methylprop-2-enylidene] malononitrile (DCTB) matrix solutions were made up to a concentration of $20 \mathrm{mg} \mathrm{mL}^{-1}$ in DCM. Sample solutions were made to an approximate concentration of $5 \mathrm{mg} \mathrm{mL}^{-1}$ in DCM. Sample and matrix solutions were premixed at a ratio of $1: 10$ or $1: 40(\mathrm{v} / \mathrm{v})$. A volume of $0.5 \mu \mathrm{L}$ of this mixture was dispensed on a MALDI steel target plate. After evaporation of the solvent, the target was inserted into a mass spectrometer.

Single crystals of 5, Nap-Cn and Cyc-C4 were mounted onto a 400/50 MicroMesh ${ }^{\mathrm{TM}}$ with NVH Oil, and transferred to a Bruker SMART APEX CCD X-ray diffractometer equipped with a graphite-monochromator. The system was controlled 
by a Pentium-based PC running the SMART software package. ${ }^{19}$ Data were collected using Mo-K $\alpha$ radiation $(\lambda=0.71073 \AA)$. The recorded raw data frames were subjected to integration and reduction by the SAINT program package. ${ }^{20}$ The structure was solved and refined by the SHELXTL software package. ${ }^{21}$ The CCDC numbers for 5, Nap-C6, Nap-C4 and Cyc-C4 are 2021545, 2021543, 2021544 and 2021547, respectively.

\section{Procedures}

Synthesis of 3: Compound 1 (0.125 g, $0.44 \mathrm{mmol})$, boronic acid $2(0.199 \mathrm{~g}, 1.31 \mathrm{mmol}), \mathrm{Pd}\left(\mathrm{PPh}_{3}\right)_{4}(40 \mathrm{mg}$, $0.03 \mathrm{mmol})$, and $\mathrm{Na}_{2} \mathrm{CO}_{3}(0.185 \mathrm{~g}, 1.75 \mathrm{mmol})$ were added to a thoroughly Ar-purged mixture of 1,4-dioxane $(10 \mathrm{~mL})$ and water $(2 \mathrm{~mL})$. The resulting reaction mixture was heated at $90^{\circ} \mathrm{C}$ for $2 \mathrm{~h}$. After cooling to RT, the reaction was hydrolyzed by adding excess water. The organic layer was separated and the aqueous part was extracted with DCM $(3 \times 10 \mathrm{~mL})$. The combined organic extracts were washed with brine, dried $\left(\mathrm{MgSO}_{4}\right)$, and concentrated in vacuo. The residue thus obtained was purified by FC (silica gel, hexane:DCM $=3: 2)$ to give $3(0.130 \mathrm{~g}, 87 \%)$ as a white solid, as a mixture of syn- and anti-diastereomers.

${ }^{1} \mathrm{H}$ NMR (500 MHz, $\left.\mathrm{CDCl}_{3}\right): \delta=7.64(\mathrm{~m}, 2 \mathrm{H}, \mathrm{H}-\mathrm{C}(3))$, 7.47-7.39 (m, 6 H, H-C(4'), H-C(4), H-C(2)), 7.37 ( $\mathrm{m}, 2 \mathrm{H}, \mathrm{H}-$ $\left.\mathrm{C}\left(6^{\prime}\right)\right), 7.13-7.07\left(\mathrm{~m}, 4 \mathrm{H}, \mathrm{H}-\mathrm{C}\left(5^{\prime}\right), \mathrm{H}-\mathrm{C}\left(3^{\prime}\right)\right), 3.74$ (d, $\left.J=4.6 \mathrm{~Hz}, 6 \mathrm{H}, \mathrm{H}-\mathrm{C}\left(7^{\prime}\right)\right)$.

${ }^{13} \mathrm{C}$ NMR (125 MHz, $\left.\mathrm{CDCl}_{3}\right): \delta=157.27-157.25\left(\mathrm{C}^{\prime}\right)$, 136.98-136.90 (C1), 132.21-132.12 (C4a), 132.06 (C6'), 129.92-129.88 (C1'), 128.88-128.86 (C4'), 127.07-127.04 (C2), 126.13-126.09 (C3), 125.03-124.99 (C4), 120.49120.46 (C5'), 110.95-110.93 (C3'), 55.57-55.53 (C7').

HR-ESI-MS $m / z(\%)$ : $363.1352\left(100,[\mathrm{M}+\mathrm{Na}]^{+}\right)$calcd. for $\mathrm{C}_{24} \mathrm{H}_{20} \mathrm{O}_{2} \mathrm{Na}^{+}$: 363.1361 .

Synthesis of 4: To anhydrous DCM $(10 \mathrm{~mL})$, purged with argon in a two-necked flask was added 3 (0.113 g, $0.33 \mathrm{mmol}$ ) and the solution was kept in an ice bath. Boron tribromide (1 $\mathrm{M}$ in anhydrous DCM, $1 \mathrm{~mL}$ ) was added dropwise and kept for $0.5 \mathrm{~h}$ before stirring it at RT for $6 \mathrm{~h}$. Water was added to it under an ice bath, and the DCM layer was separated followed by extraction of the aqueous layer once with $20 \mathrm{~mL}$ DCM. The organic layers were mixed up, dried over $\mathrm{MgSO}_{4}$, and DCM was distilled off in a rotary evaporator to yield the crude product. Further treatment of the crude product by FC (1:4 EtOAc/hexane, silica) afforded the pure off-white solid $4(0.08 \mathrm{~g}, 78 \%)$.

${ }^{1} \mathrm{H}$ NMR (500 MHz, $\mathrm{CDCl}_{3}$ ): $\delta=7.79-7.73(\mathrm{~m}, 2 \mathrm{H}, \mathrm{H}-\mathrm{C}$ (4)), 7.57-7.53 (m, $4 \mathrm{H}, \mathrm{H}-\mathrm{C}(3), \mathrm{H}-\mathrm{C}(2)), 7.40$ (m, $2 \mathrm{H}, \mathrm{H}-\mathrm{C}$ $\left.\left(4^{\prime}\right)\right)$, 7.32-7.27 (m, $\left.2 \mathrm{H}, \mathrm{H}-\mathrm{C}\left(6^{\prime}\right)\right), 7.12-7.05$ (m, $4 \mathrm{H}, \mathrm{H}-\mathrm{C}\left(3^{\prime}\right)$, $\left.\mathrm{H}-\mathrm{C}\left(5^{\prime}\right)\right), 4.81$ (d, $\left.2 \mathrm{H}, \mathrm{O}-\mathrm{H}\right)$.

${ }^{13} \mathrm{C}$ NMR (125 MHz, $\left.\mathrm{CDCl}_{3}\right): \delta=153.13-153.12\left(\mathrm{C2}^{\prime}\right)$, 134.67-134.60 (C1), 132.49-132.44 (C4a), 131.31-131.23
(C6'), 129.69 (C4'), 128.74-128.70 (C2), 126.60-126.57 (C3), 126.55-126.51 (C4), 126.27 (C1'), 120.69-120.67 (C5'), $115.71-115.68\left(\mathrm{C}^{\prime}\right)$.

HR-ESI-MS $m / z(\%): 335.1052\left(100,[\mathrm{M}+\mathrm{Na}]^{+}\right)$calcd. for $\mathrm{C}_{22} \mathrm{H}_{16} \mathrm{O}_{2} \mathrm{Na}^{+}$: 335.1048 .

Synthesis of Nap-C6: Potassium hydroxide pellets (56.1 mg, $1 \mathrm{mmol}$ ) were added to a solution of $4(0.034 \mathrm{~g}$, $0.11 \mathrm{mmol}$ ) in anhydrous dimethylsulfoxide (1 mL) kept under Ar. The color changed to brown confirming the formation of the dipotassio-derivative of 4 in $20 \mathrm{~min}$. Then the resulting base was quenched by addition of 1,6dibromohexane $(0.013 \mathrm{~g}, 0.05 \mathrm{mmol})$ via a microsyringe and stirred for an additional $0.5 \mathrm{~h}$ before heating it at $40{ }^{\circ} \mathrm{C}$ for $12 \mathrm{~h}$. The solution was then hydrolyzed by adding excess water $(30 \mathrm{~mL})$ and stirring for $0.5 \mathrm{~h}$. The resulting solution was extracted with $\mathrm{DCM}$, dried (over $\mathrm{MgSO}_{4}$ ), and the solvent was distilled off in a rotavapor. The thus obtained residue was subjected to FC (silica, hexane) to afford a pure white solid, Nap-C6 (18 mg, 41\%).

${ }^{1} \mathrm{H}$ NMR $\left(500 \mathrm{MHz}, \mathrm{CDCl}_{3}\right): \delta=7.60-7.58(\mathrm{~m}, 2 \mathrm{H}, \mathrm{H}-\mathrm{C}$ (4)), 7.48-7.46 (m, $\left.2 \mathrm{H}, \mathrm{H}-\mathrm{C}\left(6^{\prime}\right)\right), 7.43-7.39$ (m, $4 \mathrm{H}, \mathrm{H}-\mathrm{C}(3)$, $\left.\mathrm{H}-\mathrm{C}\left(4^{\prime}\right)\right), 7.36$ (dd, $\left.J=6.8,1.4 \mathrm{~Hz}, 2 \mathrm{H}, \mathrm{H}-\mathrm{C}(2)\right), 7.18$ (td, $\left.J=7.4,1.1 \mathrm{~Hz}, 2 \mathrm{H}, \mathrm{H}-\mathrm{C}\left(5^{\prime}\right)\right), 7.04(\mathrm{dd}, J=8.2,1.1 \mathrm{~Hz}, 2 \mathrm{H}$, $\left.\mathrm{H}-\mathrm{C}\left(3^{\prime}\right)\right), 3.63$ (m, $\left.4 \mathrm{H}, \mathrm{H}-\mathrm{C}\left(7^{\prime}\right)\right), 1.29-1.20$ (m, $\left.4 \mathrm{H}, \mathrm{H}-\mathrm{C}\left(8^{\prime}\right)\right)$, 0.62-0.49 (m, $4 \mathrm{H}, \mathrm{H}-\mathrm{C}(9))$.

${ }^{13} \mathrm{C} \mathrm{NMR}\left(125 \mathrm{MHz}, \mathrm{CDCl}_{3}\right): \delta=157.42\left(\mathrm{C}^{\prime}\right), 136.92$ (C1), 132.39 (C4a), 131.95 (C1'), $130.78\left(\mathrm{C}^{\prime}\right), 128.95$ (C4'), 126.70 (C2), 126.10 (C4), 124.94 (C3), 121.55 (C5'), 115.37 (C3'), 70.15 (C7'), 29.64 (C8'), 25.95 (C9).

HR-ESI-MS $m / z(\%): 417.1836\left(100,[\mathrm{M}+\mathrm{Na}]^{+}\right)$calcd. for $\mathrm{C}_{28} \mathrm{H}_{26} \mathrm{O}_{2} \mathrm{Na}^{+}$: 417.1830 .

Synthesis of Nap-C4: Nap-C4 was synthesized from compound $4(0.062 \mathrm{~g}, 0.20 \mathrm{mmol})$, potassium hydroxide $(0.044 \mathrm{~g}, \quad 0.80 \mathrm{mmol})$, and 1,4-dibromobutane $(0.022 \mathrm{~g}$, $0.06 \mathrm{mmol}$ ) via a similar procedure to that used for NPThC6. NPTh-C4 was obtained as a white solid (20 mg, 27\%).

${ }^{1} \mathrm{H}$ NMR $\left(500 \mathrm{MHz}, \mathrm{CDCl}_{3}\right): \delta=7.68(\mathrm{dd}, J=7.4,1.8 \mathrm{~Hz}$, $\left.2 \mathrm{H}, \mathrm{H}-\mathrm{C}\left(6^{\prime}\right)\right)$, 7.57-7.55 (m, $\left.2 \mathrm{H}, \mathrm{H}-\mathrm{C}(4)\right), 7.41-7.37$ ( $\mathrm{m}, 4 \mathrm{H}$, $\left.\mathrm{H}-\mathrm{C}(3), \mathrm{H}-\mathrm{C}\left(4^{\prime}\right)\right), 7.34$ (dd, $\left.J=6.8,1.2 \mathrm{~Hz}, 2 \mathrm{H}, \mathrm{H}-\mathrm{C}(2)\right), 7.23$ $\left(\mathrm{td}, J=7.4,1.1 \mathrm{~Hz}, 2 \mathrm{H}, \mathrm{H}-\mathrm{C}\left(5^{\prime}\right)\right), 6.96(\mathrm{dd}, J=8.0,1.2 \mathrm{~Hz}, 2$ $\left.\mathrm{H}, \mathrm{H}-\mathrm{C}\left(3^{\prime}\right)\right), 3.39\left(\mathrm{dt}, J=9.0,5.5 \mathrm{~Hz}, 2 \mathrm{H}, \mathrm{H}-\mathrm{C}\left(7^{\prime}\right)\right), 3.18-3.10$ (m, $\left.2 \mathrm{H}, \mathrm{H}-\mathrm{C}\left(7^{\prime}\right)\right), 0.85-0.76$ (m, $\left.2 \mathrm{H}, \mathrm{H}-\mathrm{C}\left(8^{\prime}\right)\right), 0.59 \mathrm{~m}, 2 \mathrm{H}$, $\left.\mathrm{H}-\mathrm{C}\left(8^{\prime}\right)\right)$.

${ }^{13} \mathrm{C}$ NMR (125 MHz, $\left.\mathrm{CDCl}_{3}\right): \delta=157.58\left(\mathrm{C}^{\prime}\right), 136.68$ (C1), 133.25 (C4a), $133.02\left(\mathrm{C} 1^{\prime}\right), 129.36\left(\mathrm{C} 6^{\prime}\right), 129.01\left(\mathrm{C} 4^{\prime}\right)$, 126.56 (C2), 126.11 (C4), 124.85 (C3), 122.24 (C5'), 117.32 (C3'), 70.15 (C7'), 25.17. (C8')

HR-ESI-MS $m / z(\%): 389.1521\left(100,[\mathrm{M}+\mathrm{Na}]^{+}\right)$calcd. for $\mathrm{C}_{26} \mathrm{H}_{22} \mathrm{O}_{2} \mathrm{Na}^{+}$: 389.1517 .

Synthesis of 5: Potassium hydroxide pellets $(0.045 \mathrm{~g}$, $0.80 \mathrm{mmol})$ were added to a solution of $4(0.062 \mathrm{~g}$, $0.20 \mathrm{mmol}$ ) in anhydrous dimethylsulfoxide (2 mL) kept under $\mathrm{Ar}$ in an ice bath under dark. The color changed to brown due to the formation of the dipotassio-derivative of 6 
in $20 \mathrm{~min}$. Then the resulting base was quenched by addition of 1,3-dibromopropane $(0.012 \mathrm{~g}, 0.06 \mathrm{mmol})$ via a microsyringe and stirred for an additional $0.5 \mathrm{~h}$ before raising the temperature to $60{ }^{\circ} \mathrm{C}$ for $12 \mathrm{~h}$. Elevation of temperature had no effect as monitored by thin-layer chromatography. The solution was then hydrolyzed by adding excess water $(50 \mathrm{~mL})$ and stirring for $0.5 \mathrm{~h}$. The resulting solution was extracted with DCM, dried (over $\mathrm{MgSO}_{4}$ ), and the solvent was distilled off in a rotavapor. The thus obtained residue was subjected to FC (silica, hexane) to afford 5 as a white solid (0.015 g, 19\%).

${ }^{1} \mathrm{H}$ NMR $\left(400 \mathrm{MHz}, \mathrm{CDCl}_{3}\right): \delta=7.63(\mathrm{dd}, J=7.4$, $2.3 \mathrm{~Hz}, 2 \mathrm{H}), 7.46-7.31(\mathrm{~m}, 8 \mathrm{H}), 7.14-7.02(\mathrm{~m}, 4 \mathrm{H})$, 5.84-5.70 (m, $2 \mathrm{H})$, 5.07-4.92 (m, $4 \mathrm{H}), 4.53-4.41$ (m, $4 \mathrm{H})$.

HR-ESI-MS $m / z(\%): 415.1689\left(100,[\mathrm{M}+\mathrm{Na}]^{+}\right)$calcd. for $\mathrm{C}_{28} \mathrm{H}_{24} \mathrm{O}_{2} \mathrm{Na}^{+}$: 415.1674 .

Synthesis of 7: Compound $6(0.500 \mathrm{~g}, 1.75 \mathrm{mmol})$, boronic acid $2(0.796 \mathrm{~g}, 5.24 \mathrm{mmol}), \mathrm{Pd}\left(\mathrm{PPh}_{3}\right)_{4}(0.101 \mathrm{mg}$, $0.08 \mathrm{mmol})$, and $\mathrm{Na}_{2} \mathrm{CO}_{3}(1.86 \mathrm{~g}, 17.50 \mathrm{mmol})$ were added to a thoroughly Ar-purged mixture of 1,4-dioxane $(20 \mathrm{~mL})$ and water $(4 \mathrm{~mL})$. The resulting reaction mixture was heated at $95^{\circ} \mathrm{C}$ for $12 \mathrm{~h}$. After cooling to RT, the reaction was hydrolyzed by adding excess water. The organic layer was separated and the aqueous part was extracted with DCM $(3 \times 20 \mathrm{~mL})$. The combined organic extracts were washed with brine, dried (over $\mathrm{MgSO}_{4}$ ), and concentrated in vacuo. The thus obtained residue was purified by FC (silica gel, hexane/DCM $=1 / 1)$ to give $7(0.478 \mathrm{~g}, 80 \%)$ as white powder.

${ }^{1} \mathrm{H}$ NMR (400 MHz, $\left.\mathrm{CDCl}_{3}\right): \delta=7.99(\mathrm{~d}, J=1.9 \mathrm{~Hz}, 2 \mathrm{H}$, $\mathrm{H}-\mathrm{C}(1)), 7.91$ (d, $J=8.4 \mathrm{~Hz}, 2 \mathrm{H}, \mathrm{H}-\mathrm{C}(4)), 7.72-7.69(\mathrm{~m}, 2 \mathrm{H}$, $\mathrm{H}-\mathrm{C}(3)), 7.47$ (dd, $\left.J=7.5,1.8 \mathrm{~Hz}, 2 \mathrm{H}, \mathrm{H}-\mathrm{C}\left(6^{\prime}\right)\right), 7.38(\mathrm{~m}, 2 \mathrm{H}$, $\left.\mathrm{H}-\mathrm{C}\left(4^{\prime}\right)\right), 7.12\left(\mathrm{td}, J=7.4,1.1 \mathrm{~Hz}, 2 \mathrm{H}, \mathrm{H}-\mathrm{C}\left(5^{\prime}\right)\right), 7.06$ (d, $\left.J=8.3 \mathrm{~Hz}, 2 \mathrm{H}, \mathrm{H}-\mathrm{C}\left(3^{\prime}\right)\right)$, 3.85 (s, $6 \mathrm{H}, \mathrm{H}-\mathrm{C}\left(7^{\prime}\right)$ ).

${ }^{13} \mathrm{C}$ NMR (100 MHz, $\left.\mathrm{CDCl}_{3}\right): \delta=156.71\left(\mathrm{C}^{\prime}\right), 136.15$ (C2), 132.37 (C4a), 131.08 (C6'), 130.85 (C1'), 128.68(C4'), 128.14 (C3), 127.83 (C1), 127.37 (C4), 120.92 (C5'), 111.40 (C3'), $55.64\left(\mathrm{C}^{\prime}\right)$.

HR-ESI-MS $m / z(\%): 363.1352\left(100,[\mathrm{M}+\mathrm{Na}]^{+}\right)$calcd. for $\mathrm{C}_{24} \mathrm{H}_{20} \mathrm{O}_{2} \mathrm{Na}^{+}$: 363.1368 .

Synthesis of 8 : To anhydrous DCM $(10 \mathrm{~mL})$ purged with argon in a two-necked flask was added 7 (0.478 g, $1.39 \mathrm{mmol}$ ) and the solution was kept at $-20{ }^{\circ} \mathrm{C}$. Boron tribromide ( $1 \mathrm{M}$ in anhydrous DCM, $3 \mathrm{~mL}$ ) was added dropwise and kept for $0.5 \mathrm{~h}$ before stirring it at RT for $6 \mathrm{~h}$. Water was added to it under an ice bath, and the DCM layer was separated followed by extraction of the aqueous layer once with $20 \mathrm{~mL}$ DCM. The organic layers were mixed up, dried over $\mathrm{MgSO}_{4}$, and DCM was distilled off in a rotary evaporator to yield the crude product. Further treatment of the crude product with FC (1:3 EtOAc/hexane, silica) afforded the pure off-white solid $6(0.330 \mathrm{~g}, 76 \%)$.

${ }^{1} \mathrm{H}$ NMR (500 MHz, $\left.\mathrm{CDCl}_{3}\right): \delta=8.02-8.00(\mathrm{~m}, 4 \mathrm{H}, \mathrm{H}-\mathrm{C}$ (1) and $\mathrm{H}-\mathrm{C}(4)), 7.67-7.65$ (m, $2 \mathrm{H}, \mathrm{H}-\mathrm{C}(3), 7.38$ (m, $2 \mathrm{H}, \mathrm{H}-\mathrm{C}$
(6')), 7.35-7.29 (m, $\left.2 \mathrm{H}, \mathrm{H}-\mathrm{C}\left(4^{\prime}\right)\right), 7.09-7.02$ (m, $4 \mathrm{H}, \mathrm{H}-\mathrm{C}\left(5^{\prime}\right)$, $\left.\mathrm{H}-\mathrm{C}\left(3^{\prime}\right)\right), 5.27$ (s, $\left.2 \mathrm{H}, \mathrm{O}-\mathrm{H}\right)$.

${ }^{13} \mathrm{CNMR}\left(126 \mathrm{MHz}, \mathrm{CDCl}_{3}\right): \delta=152.60\left(\mathrm{C}^{\prime}\right), 135.19(\mathrm{C} 2)$, 132.87 (C4a), 130.47 (C6'), 129.38 (C4'), 129.17(C4), 127.94 (C3), 127.90 (C1'), 127.73 (C1), 121.05 (C5), 116.01 (C3'). HR-ESI-MS $m / z(\%): 335.1051\left(100,[\mathrm{M}+\mathrm{Na}]^{+}\right)$calcd. for $\mathrm{C}_{22} \mathrm{H}_{16} \mathrm{O}_{2} \mathrm{Na}^{+}$: 335.1048 .

Synthesis of Cyc-C6: Potassium hydroxide pellets $(0.108 \mathrm{mg}, 1.92 \mathrm{mmol})$ were added to a solution of 8 $(0.100 \mathrm{~g}, 0.32 \mathrm{mmol})$ in anhydrous dimethylsulfoxide (3 $\mathrm{mL}$ ) kept under $\mathrm{Ar}$ in an ice bath in the dark. The color changed to greenish brown, so confirming the formation of the dipotassio-derivative of 8 in $20 \mathrm{~min}$. Then the resulting base was quenched by addition of 1,6-dibromohexane $(0.023 \mathrm{~g}, 0.09 \mathrm{mmol})$ via a microsyringe and stirred for an additional $0.5 \mathrm{~h}$ before taking it to $40-60{ }^{\circ} \mathrm{C}$ for $12 \mathrm{~h}$. The solution was then hydrolyzed by adding excess water $(50 \mathrm{~mL})$ and stirring for $0.5 \mathrm{~h}$. The resulting solution was extracted with $\mathrm{DCM}$, dried (over $\mathrm{MgSO}_{4}$ ), and the solvent was distilled off in a rotavapor. The thus obtained residue was subjected to FC (silica, hexane/EtOAc $=9 / 1)$ to afford a white solid, Cyc-C6 $(0.040 \mathrm{~g}, 16 \%)$.

${ }^{1} \mathrm{H}$ NMR $\left(400 \mathrm{MHz}, \mathrm{CDCl}_{3}\right): \delta=7.94-7.89(\mathrm{~m}, 4 \mathrm{H}, \mathrm{H}-\mathrm{C}$ (1)), 7.78 (d, $J=8.4 \mathrm{~Hz}, 4 \mathrm{H}, \mathrm{H}-\mathrm{C}(4)), 7.64$ (dd, $J=8.4$, $1.6 \mathrm{~Hz}, 4 \mathrm{H}, \mathrm{H}-\mathrm{C}(3)), 7.40$ (dd, $J=7.5,1.7 \mathrm{~Hz}, 4 \mathrm{H}, \mathrm{H}-\mathrm{C}\left(6^{\prime}\right)$ ), 7.34-7.28 (m, $\left.4 \mathrm{H}, \mathrm{H}-\mathrm{C}\left(4^{\prime}\right)\right), 7.04$ (dd, $J=7.5,1.1 \mathrm{~Hz}, 4 \mathrm{H}, \mathrm{H}-$ $\left.\mathrm{C}\left(5^{\prime}\right)\right), 6.97\left(\mathrm{dd}, J=8.3,1.0 \mathrm{~Hz}, 4 \mathrm{H}, \mathrm{H}-\mathrm{C}\left(3^{\prime}\right)\right), 3.92(\mathrm{t}$, $\left.J=6.3 \mathrm{~Hz}, 8 \mathrm{H}, \mathrm{H}-\mathrm{C}\left(7^{\prime}\right)\right), 1.66\left(\mathrm{t}, J=6.8 \mathrm{~Hz}, 8 \mathrm{H}, \mathrm{H}-\mathrm{C}\left(8^{\prime}\right)\right)$, $1.39(\mathrm{t}, J=4.1 \mathrm{~Hz}, 8 \mathrm{H}, \mathrm{H}-\mathrm{C}(9))$.

${ }^{13} \mathrm{C}$ NMR $\left(100 \mathrm{MHz}, \mathrm{CDCl}_{3}\right): \delta=156.20\left(\mathrm{C}^{\prime}\right), 136.04$ (C2), 132.21 (C4a), 131.04 (C6'), $130.86\left(\mathrm{C1}^{\prime}\right), 128.54$ (C4'), 128.15 (C3), 127.91 (C1), 127.14 (C4), 120.76 (C5'), 112.27 (C3'), 68.29 (C7'), 29.20 (C8'), 26.03(C9).

MALDI-TOF-MS $(m / 2 z)(\%): 394.1901\left(100,[\mathrm{M} / 2]^{+}\right)$ calcd. for $\mathrm{C}_{56} \mathrm{H}_{52} \mathrm{O}_{4}{ }^{2+}$ : 394.1933 .

Synthesis of Cyc-C4: Cyc-C4 was synthesized from compound $8(0.130 \mathrm{~g}, 0.42 \mathrm{mmol})$, potassium hydroxide $(0.233 \mathrm{~g}, 4.20 \mathrm{mmol})$, and 1,4-dibromobutane $(0.027 \mathrm{~g}, 0.01 \mathrm{mmol})$ via a procedure similar to that used for Cyc-C6. Cyc-C4 was obtained as a white solid (0.020 g, 7\%).

${ }^{1} \mathrm{H}$ NMR $\left(400 \mathrm{MHz}, \mathrm{CDCl}_{3}\right): \delta=8.00-7.95(\mathrm{~m}, 4 \mathrm{H}, \mathrm{H}-\mathrm{C}$ (1)), 7.74-7.62 (m, $8 \mathrm{H}, \mathrm{H}-\mathrm{C}(4), \mathrm{H}-\mathrm{C}(3)), 7.43$ (dd, $J=7.6$, $\left.1.7 \mathrm{~Hz}, 4 \mathrm{H}, \mathrm{H}-\mathrm{C}\left(6^{\prime}\right)\right), 7.30$ (ddd, $J=8.2,7.4,1.8 \mathrm{~Hz}, 4 \mathrm{H}, \mathrm{H}-\mathrm{C}$ $\left.\left(4^{\prime}\right)\right), 7.03\left(\mathrm{td}, J=7.5,1.1 \mathrm{~Hz}, 4 \mathrm{H}, \mathrm{H}-\mathrm{C}\left(5^{\prime}\right)\right), 6.96(\mathrm{dd}, J=8.3$, $\left.1.1 \mathrm{~Hz}, 4 \mathrm{H}, \mathrm{H}-\mathrm{C}\left(3^{\prime}\right)\right), 3.98$ (s, $\left.8 \mathrm{H}, \mathrm{H}-\mathrm{C}\left(7^{\prime}\right)\right), 1.88$ (s, $8 \mathrm{H}, \mathrm{H}-\mathrm{C}$ $\left.\left(8^{\prime}\right)\right)$.

${ }^{13} \mathrm{C}$ NMR $\left(100 \mathrm{MHz}, \mathrm{CDCl}_{3}\right): \delta=156.06\left(\mathrm{C}^{\prime}\right), 135.88$ (C2), 132.21 (C4a), 131.05 (C6'), $130.58\left(\mathrm{C1}^{\prime}\right), 128.51$ (C4'), 128.10 (C3), 127.91 (C1), 127.18 (C4), 120.81(C5'), 111.88 (C3'), 68.04 (C7'), 26.63 (C8').

MALDI-TOF-MS (m/2z) (\%): $366.161\left(100,[\mathrm{M} / 2]^{+}\right)$calcd. for $\mathrm{C}_{52} \mathrm{H}_{44} \mathrm{O}_{4}{ }^{2+}$ : 366.162 . 


\section{Funding Information}

This research was supported by the European Research Council (ERC) under the European Union's Horizon 2020 research and innovation program (Grant Agreement No. 850836, ERC Starting Grant "PolyHelix"). A.B. is supported by a PBC fellowship.

\section{Supporting Information}

Supporting Information for this article is available online at http://doi.org/10.1055/s-0040-1721102.

\section{References}

(1) Pascal, R. A. Jr Chem. Rev. 2006, 106, 4809.

(2) Xiao, J.; Duong, H. M.; Liu, Y.; Shi, W.; Ji, L.; Li, G.; Li, S.; Liu, X-W.; Ma, J.; Wudl, F.; Zhang, Q. Angew. Chem. Int. Ed. 2012, 51, 6094.

(3) Bedi, A.; Gidron, O. Acc. Chem. Res. 2019, 52, 2482.

(4) (a) Rickhaus, M.; Mayor, M.; Juríček, M. Chem. Soc. Rev. 2017, 46, 1643. (b) Kiran, V.; Mathew, S. P.; Cohen, S. R.; Hernández Delgado, I.; Lacour, J.; Naaman, R. Adv. Mater. 2016, 28, 1957.

(5) Yan, L.; Popescu, F.; Rao, M. R.; Meng, H.; Perepichka, D. F. Adv. Electron. Mater. 2017, 3, 1600556.

(6) Rickhaus, M.; Mayor, M.; Juríček, M. Chem. Soc. Rev. 2016, 45, 1542.
(7) Sim, G. Acta Crystallogr., Sect. B: Struct. Sci. 1982, 38, 623.

(8) Yamamoto, K.; Oyamada, N.; Xia, S.; Kobayashi, Y.; Yamaguchi, M.; Maeda, H.; Nishihara, H.; Uchimaru, T.; Kwon, E. J. Am. Chem. Soc. 2013, 135, 16526.

(9) Ghasemabadi, P. G.; Yao, T.; Bodwell, G. J. Chem. Soc. Rev. 2015 , $44,6494$.

(10) (a) Haenel, M. W. Chem. Ber. 1982, 115, 1425. (b) Haenel, M. W. Chem. Ber. 1978, 111, 1789.

(11) Blank, N. E.; Haenel, M. W.; Krüger, C.; Tsay, Y-H.; Wientges, H. Angew. Chem. Int. Ed. 1988, 27, 1064.

(12) Biswas, S.; Qiu, C. S.; Dawe, L. N.; Zhao, Y.; Bodwell, G. J. Angew. Chem. Int. Ed. 2019, 58, 9166.

(13) Bedi, A.; Shimon, L. J. W.; Gidron, O. J. Am. Chem. Soc. 2018, 140, 8086.

(14) Bedi, A.; Gidron, O. Chem. Eur. J. 2019, 25, 3279.

(15) Bedi, A.; Carmieli, R.; Gidron, O. Chem. Commun. 2019, 55, 6022.

(16) Haddon, R. C. Acc. Chem. Res. 1988, 21, 243.

(17) Białek, M. J.; Zaręba, J. K.; Janczak, J.; Zoń, J. Cryst. Growth Des. 2013, 13, 4039.

(18) Rashkin, M. J.; Hughes, R. M.; Calloway, N. T.; Waters, M. L. J. Am. Chem. Soc. 2004, 126, 13320.

(19) SMART-NT V5.6, BRUKER AXS GMBH, D-76181 Karlsruhe, Germany, 2002.

(20) SAINT-NT V5.0, BRUKER AXS GMBH, D-76181 Karlsruhe, Germany, 2002.

(21) SHELXTL-NT V6.1, BRUKER AXS GMBH, D-76181 Karlsruhe, Germany, 2002 